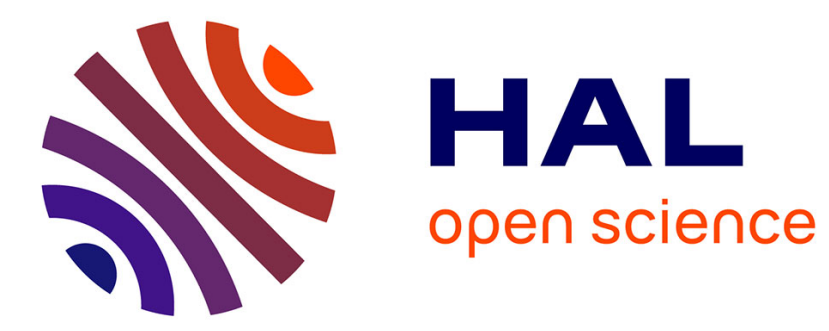

\title{
Collaborative Information Retrieval: Concepts, Models and Evaluation
}

\author{
Lynda Tamine, Laure Soulier
}

\section{To cite this version:}

Lynda Tamine, Laure Soulier. Collaborative Information Retrieval: Concepts, Models and Evaluation. Advances in Information Retrieval - 38th European Conference on IR Research, ECIR 2016, Mar 2016, Padua, Italy. pp.885-888, 10.1007/978-3-319-30671-1_86 . hal-01296314

\section{HAL Id: hal-01296314 https://hal.sorbonne-universite.fr/hal-01296314}

Submitted on 31 Mar 2016

HAL is a multi-disciplinary open access archive for the deposit and dissemination of scientific research documents, whether they are published or not. The documents may come from teaching and research institutions in France or abroad, or from public or private research centers.
L'archive ouverte pluridisciplinaire HAL, est destinée au dépôt et à la diffusion de documents scientifiques de niveau recherche, publiés ou non, émanant des établissements d'enseignement et de recherche français ou étrangers, des laboratoires publics ou privés. 


\title{
Collaborative Information Retrieval: Concepts, Models and Evaluation
}

\author{
Lynda Tamine ${ }^{1}$ and Laure Soulier ${ }^{2}$ \\ 1 University of Toulouse UPS, IRIT \\ 118 route de Narbonne - 31062 Toulouse Cedex 9 \\ tamine@irit.fr \\ 2 Sorbonne Universités, UPMC Univ Paris 06, UMR 7606, LIP6, F-75005, Paris, \\ France \\ CNRS, UMR 7606, LIP6, F-75005, Paris, France \\ Laure.Soulier@lip6.fr
}

\begin{abstract}
Recent work have shown the potential of collaboration for solving complex or exploratory search tasks allowing to achieve synergic effects with respect to individual search, which is the prevalent information retrieval (IR) setting this last decade. This interactive multi-user context gives rise to several challenges in IR. One main challenge relies on the adaptation of IR techniques or models [8] in order to build algorithmic supports of collaboration distributing documents among users. The second challenge is related to the design of Collaborative Information Retrieval (CIR) models and their effectiveness evaluation since individual IR frameworks and measures do not totally fit with the collaboration paradigms. In this tutorial, we address the second challenge and present first a general overview of collaborative search introducing the main underlying notions. Then, we focus on related work dealing with collaborative ranking models and their effectiveness evaluation. Our primary objective is to introduce these notions by highlighting how and why they should be different from individual IR in order to give participants the main clues for investigating new research directions in this domain with a deep understanding of current CIR work.
\end{abstract}

Keywords: Collaborative Information Retrieval, Collaboration, Search Process, Ranking Model, Evaluation

\section{Introduction and Tutorial Objectives}

Traditional conceptualizations of an IR task generally rely on an individual user's perspective. Accordingly, a great amount of research in the IR domain mostly dealt with both the design of enhanced document ranking models and a deep user's behavior understanding with the aim of improving an individual search effectiveness. However, in practice, collaboration among a community of users is increasingly acknowledged as an effective mean for gathering the complementary skills and/or knowledge of individual users in order to solve complex shared search tasks, such as fact-finding tasks (e.g., travel planning) or exploratory 
search tasks $[13,18]$. Collaboration allows the group achieving a result that is more effective than the simple aggregation of the individual results [14]. This class of complex search settings frequently occurs within a wide-range of domainapplications, such as the medical domain, the legal domain or the librarian domain to cite but a few. CIR results in collaborative information behavior processes, such as information sharing, evaluation, synthesis and sense-making. Two fundamental research challenges are faced by the design of CIR systems [8]: 1) allowing effective communication and coordination among the collaborators and 2) achieving high synergic effectiveness of the search results.

This tutorial focuses on the second challenge and pay a great deal of attention to how collaboration could be integrated in IR models and effectiveness evaluation processes. Our goal is to provide concepts and motivation to researchers so that participants could investigate this emerging IR domain as well as giving them some clues on how to experiment their models. More specifically, the tutorial aims to:

1. Give an overview of the concepts underlying collaborative information behavior and retrieval;

2. Present state-of-the art retrieval techniques and models that tackle the search effectiveness challenge;

3. Synthesize the metrics used for the evaluation of the effectiveness of CIR systems.

\section{Outline}

Part 1: Collaborative Information Retrieval Fundamental Notions

In this part, our primary objective is specifically to propose a broad review of collaborative search by presenting a detailed notion of collaboration in a search context including its definition $[6,20]$, dimensions $[2,5]$, paradigms $[4,9]$, and underlying behavioral search process $[3,7]$.

\section{Notion of collaboration in information seeking and retrieval \\ 2. Dimensions of Collaboration \\ 3. Collaboration Paradigms \\ 4. Behavior Processes}

\footnotetext{
Part 2: Models and Techniques for Collaborative Document Seeking and Retrieval

CIR models provide an algorithmic mediation that enables to leverage from collaborators' actions in order to enhance the effectiveness of the search process [19]. In this context, previous work have been proposed, characterized by two common axes based on the relevance judgment integration and the division of labor paradigm. While the integration of relevance judgments is issued from interactive and contextual search, division of labor is an intrinsic feature of collaboration and represents the most common paradigm integrated in CIR models
} 
since it avoids redundant actions between collaborators. Among the multiple possible types of division of labor, only the algorithmic and the role-based ones are appropriate for the CIR domain [9]. One of the main approaches relies on the search strategy differences between collaborators using roles $[12,15,16,17,19]$, where the algorithmic-based division of labor considers that users have similar objectives (in this case, users could be seen as peers) [4, 11]. These approaches are contrasted to the ones surrounded by a division of labor guided by collaborators' roles in which users are characterized by asymmetric roles with distinct search strategies or intrinsic peculiarities.

\section{Algorithmic-Driven Division of Labor-based Document Ranking models \\ 2. Role-Based Document Ranking Models}

Part 3: Effectiveness Evaluation of Collaborative Document Seeking and Retrieval

Due to the complexity of the collaborative search setting, its evaluation is challenging and constitutes an opened perspective in CIS and CIR [13]. Indeed, the high-level on heterogeneous interactions engaged for the coordination and the collective sense-making necessary to solve a shared information need raise new issues not yet tackled in interactive and contextual search. Concerning the IR aspects, the goal of this evaluation is no longer limited to the assessment of the document relevance with respect to a query, but rather the collective relevance in response to the information need expressed by all users. While the evaluation of individual IR depends only on the query and, in the case of personalized IR, the user, evaluating collaborative ranking models and techniques should consider the aspects connected to the collaboration. We present in this section, for both CIS and CIR, the evaluation framework listing the existing protocols and the evaluation metrics.

\section{Taxonomy of evaluation methodologies}

2. Evaluation metrics

Part 4: Perspectives. Collaborative search rises several perspectives. Some of them are outlined in this tutorial. More particularly, we focus on the use of roles in collaborative search [17], the leveraging of social media [10] as well as the standardization of evaluation framework [1].

1. User-driven CIR models

2. Community-based and Social-Media-Based Collaborative Information Information Retrieval Systems

3. Standardization and CIR evaluation campaigns

\section{Part 5: Questions and Discussion with the Instructors}

We end with an open discussion with participants. 
Lynda Tamine and Laure Soulier

\section{References}

[1] L. Azzopardi, J. Pickens, T. Sakai, L. Soulier, and L. Tamine. Ecol 2015: First international workshop on the evaluation on collaborative information seeking and retrieval. In CIKM'15, pages 1943-1944, 2015.

[2] R. Capra, J. Velasco-Martin, and B. Sams. Levels of "Working Together" in Collaborative Information Seeking and Sharing. In CSCW' 10. ACM, 2010.

[3] B. M. Evans and E. H. Chi. An elaborated model of social search. Information Processing $\&$ Management (IPEM), 46(6):656-678, 2010.

[4] C. Foley and A. F. Smeaton. Synchronous Collaborative Information Retrieval: Techniques and Evaluation. In ECIR '09, pages 42-53. Springer, 2009.

[5] G. Golovchinsky, P. Qvarfordt, and J. Pickens. Collaborative Information Seeking. IEEE Computer, 42(3):47-51, 2009.

[6] B. Gray. Collaborating: finding common ground for multiparty problems. Jossey Bass Business and Management Series. Jossey-Bass, 1989.

[7] J. Hyldegärd. Beyond the Search Process - Exploring Group Members' Information Behavior in Context. IPEMM, 45(1):142-158, 2009.

[8] H. Joho, D. Hannah, and J. Jose. Revisiting IR Techniques for Collaborative Search Strategies. In ECIR '09, pages 66-77. Springer, 2009.

[9] R. Kelly and S. J. Payne. Division of labour in collaborative information seeking: Current approaches and future directions. In CIS Workshop at CSCW' 13. ACM, 2013.

[10] M. R. Morris. Collaborative Search Revisited. In $C S C W$ '13, pages 1181-1192. ACM, 2013.

[11] M. R. Morris, J. Teevan, and S. Bush. Collaborative Web Search with Personalization: Groupization, Smart Splitting, and Group Hit-highlighting. In $C S C W$ '08, pages 481-484. ACM, 2008.

[12] J. Pickens, G. Golovchinsky, C. Shah, P. Qvarfordt, and M. Back. Algorithmic Mediation for Collaborative Exploratory Search. In SIGIR '08, pages 315-322. ACM, 2008.

[13] C. Shah. Collaborative Information Seeking - The Art and Science of Making the Whole Greater than the Sum of All. pages I-XXI, 1-185, 2012.

[14] C. Shah and R. González-Ibáñez. Evaluating the Synergic Effect of Collaboration in Information Seeking. In SIGIR '11, pages 913-922. ACM, 2011.

[15] C. Shah, J. Pickens, and G. Golovchinsky. Role-based results redistribution for collaborative information retrieval. Information Processing $\&$ Management (IPESM), 46(6):773-781, 2010.

[16] L. Soulier, C. Shah, and L. Tamine. User-driven System-mediated Collaborative Information Retrieval. In SIGIR '14, pages 485-494. ACM, 2014.

[17] L. Soulier, L. Tamine, and W. Bahsoun. On domain expertise-based roles in collaborative information retrieval. Information Processing $\&$ Management (IPEM), 50(5):752-774, 2014.

[18] P. R. Spence, M. C. Reddy, and R. Hall. A Survey of Collaborative Information Seeking Practices of Academic Researchers. In SIGGROUP Conference on Supporting Group Work, GROUP '05, pages 85-88. ACM, 2005.

[19] L. Tamine and L. Soulier. Understanding the impact of the role factor in collaborative information retrieval. In CIKM'15. ACM, octobre 2015.

[20] M. B. Twidale, D. M. Nichols, and C. D. Paice. Browsing is a Collaborative Process. Information Processing \& Management (IPESM), 33(6):761-783, 1997. 